dependent on the deprivation of arterial blood. The simultaneous venous congestion which is often seen appears only to hasten the onset of the paralysis. 2. The paralysis depends on the fact that the muscle fibres perish from prolonged want of oxygen. The contractile substance coagulates, breaks up, and finally disappears. Rigor mortis is in fact induced in the affected muscles. 3. It is especially characteristic that paralysis and contraction arise simultaneously, not as in paralysis of nervous origin where contraction is a later pbenomenon and of gradual onset. 4. From the earliest moment and in quite recent cases the muscles assume the state of rigor mortis and there is the greatest obstacle to extension of the limb. 5. By contraction of the material thrown out in the attempts at repair the rigidity and contracture of the limb are made worse. 6. Ischæmic paralysis and contracture of the same nature are also seen to follow the application of Esmarch's bandage, injury to the greater vessels, and exposure to extreme degrees of cold. 7. The degree of paralysis and contraction depends upon the length of time that the blood-stream has been arrested. If the ischæmia has been extreme the most serious consequences may follow in half a day, or even less, while symptoms of a high grade of severity may result from slight constriction and pressure of several weeks' duration. This is most common after fractures of the radius. 8. The prognosis is bad, and in the worst cases involving the hand and fingers the condition is absolutely irremediable. It is better in the case of the lower limb, for here tenotomy may be practised. The slighter cases may be benefited by energetic treatment with massage, \&c. 9. Mechanical treatment is practically useless. In recent cases one would endeavour to extend the muscles ander an anæsthetic; but in those of long standing any attempt to do so would be found to break the bones or tear the tendons before the muscles would yield.

So far Volkmann, in unavoidable abbreviation, and with the single exception of Anderson's work already referred to I have failed, even with the invaluable help of Mr. Plarr, Librarian of the Royal College of Surgeons, to find aught else in medical literature upon this interesting subject. That this singular form of paralysis is due to the combined influences of pressure, fixation, and ischæmia there can hardly be a doubt, nor is there any doubt that my own case was an example of it. The rarity of the condition is probably one reason why so few cases have been placed upon record; but it is not unwarrantable to assume that some have not seen the light because, in the words of Anderson, the paralysis is "a reproach to surgery, since a careful observation of the hand and fingers during the use of splints will always give due warning of the dancer."

It is not, however, by any means so certain which are the structures upon which continuous pressure exerts this injurious influence. In the observation of $\mathrm{my}$ own case I could never believe that it was simply a nerve lesion with which we had to do. The slight ulnar paresis was obviously the result of a trifling injury to the ulnar nerve at the site of injury to the bone, and there was no reason for thinking that the pressure of the splints could have been specially exerted upon this one nerve. If upon any, the median was surely more exposed to pressure, but there was no special evidence of injury to it, and as pointed out by Volkmann the simultaneous origin of the palsy and the contracture was altogether unlike the effect of gross lesion to a nerve trunk. But the electrical observations of Dr. Wilfred Harris show indisputably that nerve elements had not escaped injury. After describing the reaction of degeneration which he discorered, he says. "Any ischæmic condition would, I imagine, damage the nerve-end-plates as well as the muscle and one might expect, I should think, some reaction of degeneration." Mr. Anderson tells me that this view coincides exactly with his own as given in a previous quotation. Dr. Harris adds in a later communication: "The fact of the great reduction to faradaism in the flexor muscles when I first saw the case suggested to me a nerve lesion, perhaps intra-muscular, and does still, since in acute myositis there are no electrical changes until the late stages when atrophy, if any, sets in. Erb, too, states positively in his book that primary muscular conditions do not cause reaction of degeneration, which is in his opinion proof of nerve lesion. But $I$ know nothing of ischæmic myositis and probably Erb did not either and the reactions may very well be a part of the condition as you suggest. The obvious answer to the difficulty would I think be supplied by experiment." I have ventured to repeat here what Dr. Harris has written to me, for he speaks with an authority on such matters to which I cannot pretend. But nothing that he tells me is, I believe, opposed to the view which I would provisionally hold as to the causation of this particular form of paralysis and contracture, that it is not primarily or even in the main due to a nerve lesion but that it is due to the combined effects of pressure, immobilisation, and greatly diminished blood-supply therefrom upon the muscular elements, the connective tissue elements, and the nervous elements which are met with in every muscle throughout the body. That pressure alone, or immobilisation alone, or deprivation of blood alone could bring about the results which are seen is not nearly so likely as the combination of all three, and there is no part of the body on which they can be so readily brought to bear as in the case of the forearm bound up and negligently left bound up after fracture. May the publication of this case be the means of making the evil consequences of such ill-treatment more widely known.

Lastly, as to the tendon-lengthening which was practised here. It seemed to me that it offered the best chances of amelioration of the distressing condition, and from personal experience of it in other instances and for other purposes I felt that the operation was one upon which we might rely. Originally performed and recommended, I believe, in this country by Anderson, and a year later in America by Keen, the operation has become a recognised procedure of much value in surgery, and has doubtless been used by many surgeons. Keen ${ }^{5}$ employed it in a case of post-hemiplegic contracture of the flexors of the fingers in a lady 25 years of age, and lengthened four tendons of the deep flexors, five of the superficial and those also of the two carpal Hexors, of the flezor longus pollicis, and of the palmaris longuis with some measure of success; and Anderson records a case of a girl, aged 17 years, with flexor contraction the result of some injury to the arm in childhood for whom he lengthened the tendons with much benefit. I am further indebted to my friend Mr. Anderson for the opportunity of reading the accounts of two other cases by Dr. Colgan and Dr. Wilson respectively, but they have no special bearing upon the subject of tendon-lengthening in such a condition as was seen in my own case. Akin to it, though owning a different cause, were the cases of Anderson and Keen; but there is, I believe, no case on record in which it has been practised in Volkmann's ischæmic paralysis. The result has far exceeded expectation, and I take it that the great improvement is due not alone to the mere fact that the tendons have been made longer, but that by their lengthening an increased range of movement has been made possible in the affected muscles. Muscles are meant for movement, and movement is an essential element in the treatment of any such affection as the peculiar contracture seen in this disease. Massage and electrical stimulation are also without donbt of inestimable value, but they are likely to fail of their purpose unless some movement is possible at the same time. At any rate, speculation apart, the result of the operation in this instance has been so satisfactory as to justify me in commending the adoption of the same method to the notice of surgeons.

\section{HYPOTHERMIA. ${ }^{1}$}

By E. B. HULBERT, M.D. DURH., M.R.C.S. ENG., L.R.C.P. LOND.

A MAN, aged 36 years, married, the father of three children, was admitted into University College Hospital under Dr. Charlton Bastian (whose clinical clerk I happened to be at the time, and for whose kind permission to make use of the notes of the case $I$ am deeply indebted) on April 16th, 1887, complaining of drowsiness and occasional frontal headache of about two years' duration. He had had scarlet fever when he was a lad and soft chancre ten years before coming under observation, but he denied syphilis. There was no history of nervous disease in the family. He

5 Transactions of the College of Physicians of Philadelphia, 1891. 8 Loc. cit., p. 58 .

1 Being a contribution to a discussion on Temperature in Health and Disease, read at a meeting of the Windsor and District Medical and Disease, read at a mect
Society on Dec. 20 th, 1899 . 
had been for some years a chemist's assistant, but had latterly been dismissed from his situation in consequence of bis marked drowsiness, which at times led to his falling asleep over his meals and when at work, and because he was not always responsible for his actions. Thus on one occasion he was found on the doorstep of a strange house far from home, and on being questioned could give no account of himself and had no recollection as to how he arrived there.

As the man remained in the hospital, with the exception of about ten weeks, until his death on Jan. 2nd, 1888, the notes of the case are naturally voluminous, and the following epitome of his leading symptoms may suffice. Delayed cerebration; occasional mild delirium, diurnal or nocturnal, and at times of a restless type; speech slow and scanning; the skin temperature was obviously depressed; pin-point pupils, reacting to accommodation but not to light ; knee-jerks and ankle clonus were absent ; no definite spasms or paralysis, either of motion or sensation, until a late period in the case, when generalised twitching movements of the limbs and face occurred; during the same time there was noted want of control over the sphincters; the pulse was regular, of fair volume, the rate varying, directly as the temperature, between the extreme limits of 36 and 170 per minute; the respirations also varied in the same manner from 10 to 48 per minute and at the close were of the Cheyne-Stokes type. The somnolence, always present, was variable in degree but increased as time wore on, and the patient finally died in a comatose condition. The diagnosis made was that of some diffuse degenerative change in the brain, possibly sclerotic in character, and beginning chiefly in the pons and medulla

A most careful post-mortem examination was made and numerous microscopical sections were cut from the cerebrum, cerebellum, pons, medulla, \&c., but no gross lesion was discovered in any part of the body.

The interest of the case is chiefly centred in the records taken of the temperature, which was taken on 88 days, commencing on Oct. 5th, 1887, several observations, even as many as 11, being made daily ; on only 18 days was the temperature found to register above $98.4^{\circ} \mathrm{F}$. The rectal thermometer, which was nsed for the majority of the readings, was made by Hawksley and was very carefully compared with a standard instrument registered at Kew, made by Casella, and great care was taken to avoid erroneous observations, thermometers being not infrequently placed simultaneously in the mouth, the rectum, the axilla, and even in the urethra. From Oct. 6th to the 16th inclusive the temperature was not accurately recorded, as the ordinary clinical thermometer used was not marked below $95^{\circ}$. The same happened on Nov. 2nd and $3 \mathrm{rd}$, and again from Nov. 9th to the 14th; the rectal instrument on this date recorded $833^{\circ}$, and on the same day, without obvious cause, the temperature rose $12 \cdot 6^{\circ}$ in nine consecutive hours, reaching $95.9^{\circ}$. Two days later it sank $13^{\circ}$ in 16 hours, the thermometer left in the rectum for half an hour marking $82 \cdot 3^{\circ}$. On the mext day the temperature was slightly lower, and on the following day the minimal temperature in this case was recorded-viz., $81.6^{\circ}$ in the rectum (half an hour's observation)-and simultaneously a surface instrument placed on the chest-wall for two hours registered $75.5^{\circ}$. At this stage a hot bath was given, the temperature of the water being gradually raised from $98^{\circ}$ to $105^{\circ}$, and the patient's temperature rose $13.1^{\circ}$ in 67 minutes and $195^{\circ}$ in 18 hours. It then became slightly raised above normal for a day or two and again descended, a reading of $90.2^{\circ}$ (skin of the chest one hour) being obtained on Nov. 21st. The descent continued with fair uniformity, successive readings of $91 \cdot 5^{\circ}$ (axilla), $89 \cdot 1^{\circ}$ (axilla), $88 \cdot 3^{\circ}$ (rectum), and $85^{\circ} 7^{\circ}$ (rectum) being obtained. An hour spent in a hot bath again produced a rise of $13.6^{\circ}$, but the effect was only temporary, $85.5^{\circ}$ (rectum) and $853^{\circ}$ (rectum) being noted. Here the temperature rose snmewhat rapidly, and shortly after death marked $104.8^{\circ}$ in the rectum.

The literature on the subject of subnormal temperature appears, on the whole, to be scanty, and it is certainly, according to $m y$ experience, widely diffuse. A brief epitome may, therefore, not be entirely out of place.

Erichsen ${ }^{2}$ says that in fracture of the lower cervical region the temperature may rise to $111^{\circ}$ or may sink to $81^{\circ}$, but that the cause is not well understood.

Roberts $^{3}$ enumerates amongst the conditions producing subnormal temperatures shock, collapse, severe injury to the upper part of the spine, some diseases of the brain or spinal cord, starvation, severe hæmorrbage, and some chronic wasting diseases-e g., cancer. Regarding cholera, he says that in the stage of collacse the temperature in the mouth ranges from $79^{\circ}$ to $88^{\circ}$, in the axilla from $90^{\circ}$ to $97^{\circ}$, but that it reaches a much higher level in the vagina and rectum. Also, "a very low temperature has been noted in carpolic acid poisoning and in sclerema neonatorum." He states, "Should the temperature fall below $93^{\circ}$ death almost always results."

Russell Reynolds ${ }^{4}$ corroborates certain of these statements.

Bristowe ${ }^{5}$ says: "In collapse-the result of severe injury - the temperature even in the rectum may fall (Wagstaffe) as low as $82 \cdot 15^{\circ}$."

Quain ${ }^{3}$ states: "A temperature of $71 \cdot 6^{\circ}$ has been observed in sclerema neonatorum." And again, "The whole range of temperature within which life can well be maintained is comprised between $90^{\circ}$ and $110^{\circ}$.

Landois and Stirling ${ }^{7}$ mention Löwenhardt as having found that "in paralytics and in insane persons several weeks before their death the rectal temperature was $86^{\circ}$ to 87. $8^{\circ}$." Also, "Beckterew found in dementia paralytica before death $81.5^{\circ}$ in the rectum; the lowest temperature observed and life retained was in a drunken person- $75.2^{\circ}$ (Reinke, Nicolaysen)."

Fagge" says: "A great lowering of temperature by force majeure, as Liebermeister terms it, is well seen in persons picked up insensible in the streets during cold weather. Cobnheim alludes to cases of this kind in which the thermometer in the rectum has not risen above $86^{\circ}, 79^{\circ}$, or even $75^{\circ}$. The pupils are then dilated ${ }^{10}$ and sluggish, whilst the pulse and the respiration are greatly reduced in frequency, but unless things have gone too far for recovery to take place such persons under suitable treatment regain their normal temperature in a few hours, or even pass into a condition of reactive pyrexia." Regarding the stage of collapse in cholera he says : "According to Goodeve a thermometer placed in the month indicates from $79^{\circ}$ to $82^{\circ}$. In the axilla, however, the temperature is seldom below $93^{\circ}$ or $94^{\circ}$ and in the rectum or vagina it rises through the period of collapse, reaching $100^{\circ}, 102^{\circ}$, or even $104^{\circ} . "$

Gould ${ }^{11}$ quotes a case recorded by Duffy in which the temperature in the mouth and axilla marked $84^{\circ}$. The patient was a negress, aged 35 years; she aborted, and death took place on the following day.

Osler ${ }^{12}$ treats the subject at greater length. Amongst conditions giving rise to a subnormal temperature be refers to: (a) Acute alcoholism, especially when aggravated by exposure to cold. Thus are explained the lowest reported temperatures. He mentions a patient who was admitied under these conditions with a temperature of about $75^{\circ}$; ten hours later the temperature had not risen to $91^{\circ}$. (b) Cerebral hæmorrhage. "Here it is of ten subnormal" (Bastian). He quotes a case in which it sank below 95. (c) Heat exhaustion, especially when combined with physical exertion. It may be as low as $95^{\circ}$ or $96^{\circ}$. (d) Acute tuberculosis. (e) Ague (cold stage). The skin temperature may be low. $(f)$ Pernicious malaria-the algide stage. (g) Chronic tuberculosis. He quotes a case in which the temperature was $95^{\circ}$. (h) Tuberculous meningitis. At the close the temperature may be as low as $94^{\circ}$. (i) Uræmic convulsions-after the attacks.

Finally, Wunderlich, in his monograph on Medical Thermometry, published by the New Sydenham Society, as the result of 16 years' assiduous work in this field, deals still more elaborately with the subject. He says : " Exceedingly low temperatures are very commonly met with in the following : In the remissions of a remittent fever ; in consequence of loss of blood or powerful evacuations; in the course of defervescence when this is excessive, and sometimes in the death struggle." Treating of collapse, he observes that the temperature very seldom sinks below $914^{\circ}$. He defines "collapse temperatures" as those below $96.8^{\circ}$ and classifies them thus: (a) deep fatal algide collapse below $92 \cdot 3^{\circ}$; (b) algide collapse from $923^{\circ}$ to $95^{\circ}$. In these

4 A System of Merlicine, vol. i , p. 691.

The Theory and Practice of Medicine sixth edition, n. 116

A Dictionary of Medicine, vol. i., p. 1600, article "Temperature." Human Physiology, second edition, vol i., p. 467 .

a Ir cality of observation not recorded.

9 The Principles and Practice of Medicine, second edition, vol. i

10 The pupils were at all times markedly contracted in the case now

recorded.

12 The Principles and Practice of Medicine, last edition 
circumstances it is possible to save life, but the patient is in the greatest danger; $(c)$ moderate collapse from $95^{\circ}$ to $968^{\circ}$; this is in itself without danger. He quotes Fleury as having observed the temperature of a subject in a cold bath sink to $932^{\circ}$, or even to $84 \cdot 2^{\circ}$. Later he says: "Although in certain cases of cholera temperatures of $78.8^{\circ}$, or even lower, have been observed on the surface of the body we may be almost sure (from other observations in the same disease) that the rectal and vaginal temperatures were considerably higher." Again: "Löwenhardt 13 has published four cases of insanity in which lower temperatures occurred than in any hitherto observed. Before death, and indeed for several days, they showed $77^{\circ}, 85.1^{\circ}, 74.7^{\circ}$, and $82.4^{\circ}$ They were very old people who got out of bed in the coldest time of the year, and ran about naked, and from their dirty habits were constantly being bathea, and who took hardly any food; in one case the pulse was only 45 , and in anotber only 23 per minute." He quotes Magnan as giving a vaginal temperature of $78.8^{\circ}$ in a drunken woman who lay out exposed to sleet all night. The temperature became normal in two days. Wunderlich states ${ }^{14}$ that the lowest temperature which he had seen followed by recovery was $92.3^{\circ}$ (the pulse beating 62 times in the minute). This was an instance of "collapse of defervescence" in enteric. Again, referring to cholera, ${ }^{15}$ he observes: "The cutaneous temperature even in the axilla during the algide stage is, as a rule, diminished, sometimes, indeed, very greatly so, yet not often below $95^{\circ}$. The temperature under the tongue may be still more diminished. In the stage of asphyxia the temperature there seldom exceeds $878^{\circ}$, and even in cases which recover may fall to about $788^{\circ}$. If it fall below this recovery would appear to be impossible." A little further on ${ }^{16}$ he quotes two cases, reported by Fischer, of injury to the cervical cord in which temperatures of $93.2^{\circ}$ (rectum) and $86.3^{\circ}$ (axilla) were recorded; and likewise a case (Wagstaffe) of fracture with dislocation of the sixth cervical vertebra where a temperature of $923^{\circ}$ was recorded on admission which sank to $81.7^{\circ}$ in the ensuing 45 hours, the patient dying three hours later. Later still, ${ }^{17}$ he refers to the influence of inanition, especially when aggravated by exposure, loss of blood, vomiting, diarrhcea, exposure to cold, \&c. Just before death the temperature may be very low, especially in the syphilitic marasmus of children, of which he gives an instance with a temperature of $77^{\circ}$ in the rectum. He also notes a case of ordinary marasmus in which the temperature was $834^{\circ}$, and declares on Roger's authority ${ }^{18}$ that the axillary temperature is very low in congenital induration of the areolar tissue (sclerema) of new-born children. Roger found that in 29 such cases the average temperature was $87.8^{\circ}$, and of these in seven cases it marked less that $788^{\circ}$

Greenhow ${ }^{19}$ has reported an axillary temperature of $84^{\circ}$, but the nature of the case is not stated, and included in the charts at the end of Wunderlich's remarkable monograph are three examples of subnormal temperatures-Fig. 10, temperature $92 \cdot 3^{\circ}$, typhoid with collapse (this patient apparently recovered); and Figs. 75 and 76 , temperatures $95^{\circ}$ and $95.1^{\circ}$ (both these patients died from acute miliary tuberculosis).

Windsor.

\section{A MODE OF OPERATING IN CASES OF APPENDICITIS,}

ADAPTED FOR USE ON ANY DAY OR AT ANY STAGE OF AN ACUTE OR SUBACUTE ATTACK, THOUGH NOT INDICATED IN EVRRY CASE.

BY C. B. KEETLEY, F.R.C.S. ENG., SURGEOY TO THE WEST LONDOY HOSPITAL.

With reference to Mr. C. Mansell Moullin's interesting paper, "Early $v$. Late Operation in Cases cf Inflamed Appendix," which appeared in THE LANCET of Dec. 16th, 1899 (p. 1657), and to Mr. James Berry's valuable letter on the same subject in THE LaNCET of Dec. 30th (p. 1857), I would call attention to the circumstance that both these gentlemen when writing of "early operation" for appendicitis evidently mean one which opens the general peritoneal

13 Loc cit., p. 204.
15 Loc, cit, p. 421.
17 Loc. cit., p. 428.

cavity and removes the appendix. I wish to describe another mode of early operation which has, I believe, certain. advantages.

I would say previously that to some extent I share $\mathbf{M r}$. Berry's belief that early operations for the removal of the appendix are occasionally performed which result in the loss of life which patience might have saved. But the cases of this kind which have come under my observation have never been very early operations. None bad beer operated on in the first 36 bours. Such a rule as that of waiting until the fifth day I should strqngly object to. believe that more cases operated on from the fifth day to the tenth day are fatal than any others. But that may be because many physicians who do not call in the surgeon till the fifth day would not call him in at all if the symptoms were less serious than those of general peritonitis or acute intestinal obstruction. Therefore I feel, and always have felt, the force of what is really the point of Mr. Moullin's paper-viz., Are we still to fold our hands and leave to chance so many cases the course of which we cannot foresee with certainty? When Mr. Berry writes that, "provided that the patient be kept absolutely at rest in bed and not disturbed by purgatives or enemata or other injudicious treatment" diffuse peritonitis rarely supervenes, he is probably right. An exceedingly able and practical physician used to make this view the basis of a firm opposition to all surgical intervention of any kind and at any time. A few years ago be suddenly veered to the other extreme, driven thither, I suspect, by a run of ill-luck. Delirium, obstinacy, disobedience, the feeling that "a good motion would relieve all the symptoms," fussy relatives, careless nursing, have all been known to disturb the perfect rest, \&c., prescribed for these cases. Another danger is that of heavy-handed palpation of a small collection of pus or of a recent extravasation. Tenderness generally prompts the patient to protect himseif from this, but when he is well dosed with opium that protection may be lost. The argument in favour of early intervention is not dependest on statistics, which, as Mr. Berry himself shows, may be easily manipulated. Still less does it rest on Mr. Moullin's personal statistics, whatever they may be.

The mode of operating which $I$ believe to be at all times safe, whether on the first or last day of an acute, a subacute.

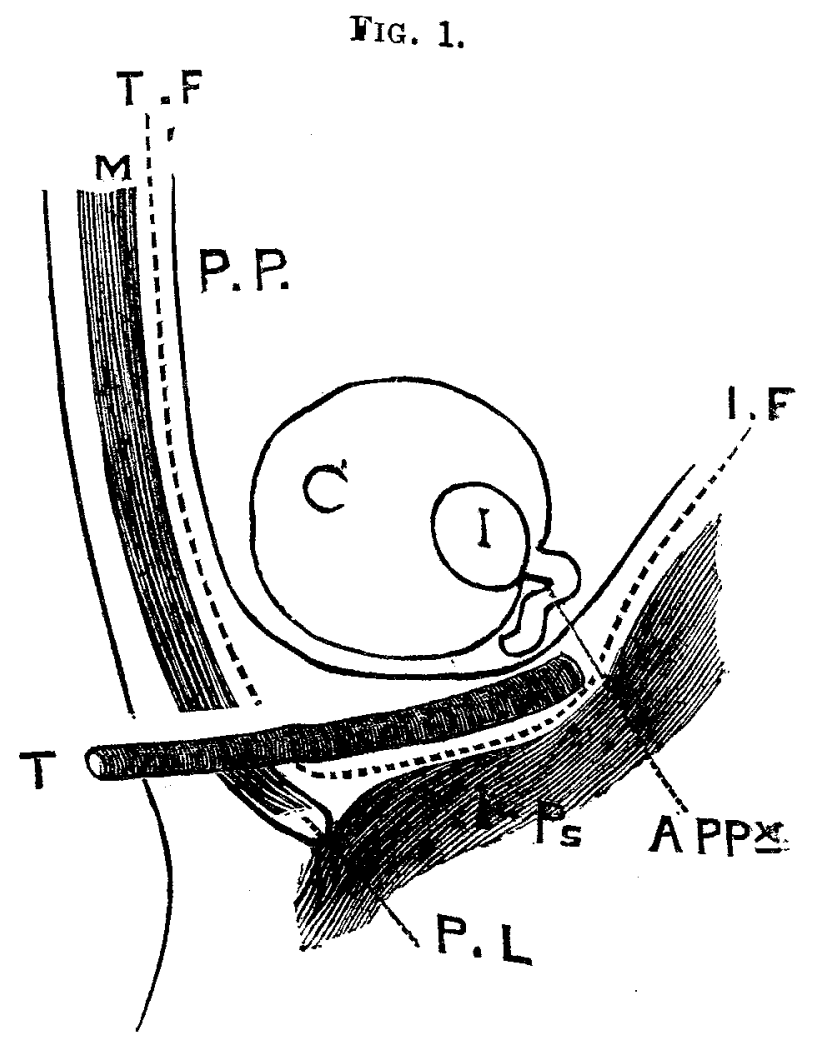

Rough diagram to illustrate the operation. T. F, Trans versalis fascia. M., Muscular and aponeurotic lavers of abdominal wall. P.P., Parietal peritoneum. C., Cxeum. formis. I-Ps., Ilio-psons muscle APPx, Appendix vermi$T$, Drainage-tube.

or a chronic attack ( $I$ do not say that it is at all times anci in all cases indicated) may be described as follows. It takes into consideration the path by which the pus, whes pus forms, usually mounts to the inguinal region of the 